This item was submitted to Loughborough's Research Repository by the author.

Items in Figshare are protected by copyright, with all rights reserved, unless otherwise indicated.

\title{
Relationships between illness representations, physical activity and depression in chronic kidney disease
}

PLEASE CITE THE PUBLISHED VERSION

https://doi.org/10.1111/jorc.12274

\section{PUBLISHER}

Wiley ( European Dialysis and Transplant Nurses Association/European Renal Care Association

\section{VERSION}

AM (Accepted Manuscript)

\section{PUBLISHER STATEMENT}

This is the peer reviewed version of the following article: NAH, R. ... et al, 2019. Relationships between illness representations, physical activity and depression in chronic kidney disease. Journal of Renal Care, 45 (2), pp.74-82, which has been published in final form at https://doi.org/10.1111/jorc.12274. This article may be used for non-commercial purposes in accordance with Wiley Terms and Conditions for Use of Self-Archived Versions.

\section{LICENCE}

CC BY-NC-ND 4.0

\section{REPOSITORY RECORD}

Nah, Ryan, Noelle Robertson, Faatihah Niyi-Odumosu, Amy L. Clarke, Nicolette Bishop, and Alice C. Smith. 2019. "Relationships Between Illness Representations, Physical Activity and Depression in Chronic Kidney Disease”. figshare. https://hdl.handle.net/2134/36630. 
1 Relationships between illness representations, physical activity and

2 depression in Chronic Kidney Disease

3

$4 \quad{ }^{1}$ Nah Ryan, ${ }^{1}$ Robertson Noelle, ${ }^{2}$ Niyi-Odumosu Faatihah A, ${ }^{3}$ Clarke Amy L,

$5 \quad{ }^{2}$ Bishop Nicolette C, ${ }^{3}$ Smith Alice C

6

7

$8{ }^{1}$ Department of Neuroscience, Psychology and Behaviour, University of Leicester,

9 United Kingdom;

10

$11{ }^{2}$ School of Sports Exercise and Health Sciences, Loughborough University, UK

13 'Leicester Kidney Lifestyle Team, John Walls Renal Unit, University Hospitals of

14 Leicester NHS Trust and Department of Health Sciences, University of Leicester,

15 UK

16

17

18 Corresponding author:

19 Professor Alice C Smith

20 Leicester Kidney Lifestyle Team

21 Academic Unit

22 Leicester General Hospital

23 Leicester LE5 4PW

24 UK

25 Tel +44 1162584346

26 Email aa50@le.ac.uk

27 


\section{Acknowledgements}

30 We gratefully acknowledge the cooperation of all of the patients and renal

31 outpatient clinic staff for their participation, support and help during the

32 recruitment process. This work was partly funded by the Stoneygate Trust

33 and supported by the School of Psychology at the University of Leicester,

34 and the National Institute for Health Research (NIHR) Leicester Biomedical

35 Research Centre. The views expressed are those of the authors and not

36 necessarily those of the NHS, the NIHR or the Department of Health.

38 Conflict of Interest Statement

39 None of the authors of this manuscript have any conflicts of interest to

40 declare. The results presented in this paper have not been published

41 previously in whole or part, except in abstract format.

\section{Corresponding Author Biodata}

44 Alice Smith is Professor of Lifestyle Medicine at the University of Leicester

45 and the University Hospitals of Leicester NHS Trust. Her primary research

46 interest is the role of physical activity, exercise and lifestyle management in

47 kidney disease. Her translational research programme encompasses

48 laboratory-based exploratory and mechanistic work, and includes outcome

49 measure evaluation, lifestyle intervention development and effectiveness

50 testing, implementation and service evaluation. A strong track record of

51 patient involvement and engagement, and qualitative exploration of patient

52 perspectives and experience underpins all the work. 


\section{Abstract}

55 Background: Chronic Kidney Disease (CKD) is exacerbated by depression 56 and confers significant healthcare costs. Whilst adverse impacts may be

57 mitigated by physical activity, many patients with CKD remain physically 58 inactive, with this physical inactivity potentially influenced by how CKD is 59 appraised.

60 Objectives: The study aims to explore the relationship between physical

61 activity, depression and illness representations in CKD.

62 Methods: Non-dialysing patients with CKD completed the Revised Illness

63 Perception Questionnaire (IPQ-R), Beck Depression Inventory (BDI-II) and

64 Short-Form International Physical Activity Questionnaire (IPAQ-SF) while

65 demographic information was obtained via medical records. Correlation and

66 regression analyses were conducted to determine the relationship of illness

67 representations with levels of physical activity. Moderation and mediation

68 analyses were performed to investigate the role of depression in any

69 relationship between illness representations and physical activity levels.

70 Results: Seventy respondents, with a mean age of $60 \pm 16$ years, the 71 majority being male (60\%), took part in the study. Of illness representation 72 dimensions, personal control was positively associated with levels of 73 physical activity $(r=.288, p<.05)$ while timeline cyclical was a significant 74 predictor (Beta=-.423, $p=.008$ ). Severity of depression was neither a 75 moderator $(b=.023,95 \% \mathrm{Cl}[-.015, .061], t=1.201, p=.23)$ nor a mediator $76(b=-.021, \mathrm{BCa} \mathrm{Cl}[-.082, .008], p=.33)$.

77 Conclusions: Facets of illness representations had significant relationships 78 with levels of physical activity. Future research concerning the development 79 and validation of psychological interventions based on an illness 80 representations framework for patients with CKD not on renal-replacement 81 therapy is proposed. The efficacy of such interventions could be then 82 evaluated using a randomised controlled method. 
85 Chronic Kidney Disease (CKD) is an irreversible long-term condition often

86 undiagnosed until an advanced stage where costs can be significant for the

87 individual and society (NICE 2015a). Adverse impacts of CKD appear

88 exacerbated by co-morbid mental health problems (Tonelli et al. 2015).

89 Depression is prevalent in individuals with CKD (EMPO 2010; NICE 2015b),

90 where 20 to 30 per cent of patients meet diagnostic criteria (Cukor et al.

91 2007) compared to point prevalence of 2 to 4 per cent in the general

92 community and 5 to 10 per cent in primary care settings (Hedayati et al.

93 2009). As CKD and depression have negative repercussions (Cruz et al.

94 2010, Farrokhi et al. 2014, Teles et al. 2014), and depression is a significant

95 co-morbidity magnifying adverse impact, increased attention has been

96 drawn to possible interventions that might mitigate the impact of both CKD

97 and depression.

99 Studies have found that engagement in physical activity and exercise

100 accrues significant physiological benefits such as improved cardiovascular

101 reactivity, eGFR and physical functioning and a reduction of inflammation

102 for individuals with CKD (Kosmadakis et al 2012, Smith \& Burton 2012,

103 Gould et al 2014, Wilkinson et al 2018). A Cochrane review reported

104 evidence demonstrating beneficial effects of physical activity on CKD and

$105 \operatorname{mood}($ Heiwe \& Jacobson 2011). 
107 Although activity and exercise have scope to mitigate the impact of CKD

108 and alleviate depression in patients with CKD, many individuals do not

109 undertake sufficient physical activity (Zamojska et al. 2006; Beddhu et al.

110 2009; Avesani et al. 2012; Hayhurst \& Ahmed 2015). Explanatory theories

111 were developed to understand such phenomena and inform health

112 behavioural change interventions (Nigg et al. 2002). Notable amongst these

113 self-regulation models is Leventhal and Cleary's Common Sense Model

114 (CSM) of illness representations (Leventhal \& Cleary 1980). The CSM

115 hypothesises that individuals with illnesses construct illness beliefs about

116 their health conditions, which influence health-related behaviours such as

117 the undertaking of physical activity.

119 Extensive research investigating how illness representations influence

120 health behaviours in chronic illnesses, notably rheumatoid arthritis, chronic

121 obstructive pulmonary disease (COPD) and multiple sclerosis (Hale et al.

122 2007) has been conducted. However, there is a paucity of research

123 exploring the relationship between illness representations and health

124 behaviour in CKD. No known studies have examined the roles of illness

125 representations in influencing the undertaking of physical activity for

126 patients with CKD particularly those not receiving renal replacement therapy

127 (also termed as patients with CKD-ND in this paper). Furthermore, illness

128 representations were found to differ between dialysing and non-dialysing

129 patients (Jansen et al. 2010; Jansen et al. 2013). 
131 Hence, the current study aimed to determine if facets of illness

132 representations are associated and predictive of levels of physical activity

133 in patients with CKD-ND. This is of clinical importance as illness

134 representations were found to be modifiable (Hale et al. 2007), potentially

135 increasing physical activity, which mitigates the impact of CKD and

136 depression. Besides that, depression was found to be associated with

137 physical activity (Jekau \& Brand 2017) and illness representations (Muscat

138 et al. 2018). Thus, the secondary study aim was to investigate if the severity

139 of depression has a moderating or mediating effect between illness

140 representations and levels of physical activity. 


\section{Materials and Methods}

143

144 Design, setting and participants

145 Participants were recruited through convenience sampling in a UK renal

146 outpatient clinic from August 2016 to January 2017. A face-to-face

147 approach was adopted whereby patients were approached randomly and

148 introduced to the study. Eligible patients met the following inclusion criteria:

149 (i) diagnosis of CKD and not on dialysis, (ii) male or female aged 18 years

150 or above, (iii) were willing and able to give informed consent for study

151 participation, and (iv) were able to complete the measures in English.

152 Participants were given a study survey booklet to be taken away,

153 completed, and returned within 10 days. Medical records were accessed

154 after completed surveys were returned to extract relevant clinical details. All

155 participants in the study provided informed consent. The study was

156 sponsored by the University Hospitals of Leicester NHS Trust and approved

157 by the London Queen Square Research Ethics Committee (ref 158 16/LO/0980).

160 Measures

161 The International Physical Activity Questionnaire Short Form (IPAQ-SF), a 162 seven-item self-report questionnaire was used to assess participants' levels 163 of physical activity, which are categorised into four intensity levels: vigorous164 intensity activity; moderate-intensity activity; walking and; sitting (Craig et 165 al. 2003). The IPAQ-SF can be calculated as a continuous score by 166 multiplying activities' metabolic equivalent (MET) with the time spent 
167 (minutes) and the number of days engaged in those activities. Individuals 168 can also be categorised into three levels of physical activity based on their

169 categorical score, specifically, 'Inactive', 'Minimally Active' and 'Health

170 Enhancing Physical Activity (HEPA) active' (IPAQ 2004).

171

172 The Beck Depression Inventory (BDI)-II, a 21-item self-report questionnaire 173 was used to assess participants' severity of cognitive and somatic 174 depressive symptoms in the past two weeks (Beck et al. 1988). Each item

175 is rated on a four-point Likert scale ranging from 0 to 3 , with higher overall

176 scores reflecting greater severity of depression (Whisman \& Richardson 177 2015). The BDI-II total score is further categorised into the following 178 depression severity categories: 'Minimal Depression' (0-13), 'Mild 179 Depression' (14-19), 'Moderate Depression' (20-28) and 'Severe 180 Depression' (29-63) (Beck et al. 1996). The BDI-II clinical cut off score of $\geq$ 18111 was established as having the best diagnostic accuracy for depressive 182 disorder in patients with CKD-ND (Hedayati et al. 2012).

184 Facets of illness representations were assessed by the Illness Perceptions 185 Questionnaire-Revised (IPQ-R). The IPQ-R is an 84-item self-report 186 questionnaire that measures the five components of CSM (Moss-Morris et 187 al. 2002). The current study utilised the second section of the IPQ-R, which 188 consists of seven subscales: consequences, timeline acute/chronic and 189 cyclical, personal and treatment control/cure, illness coherence, and 190 emotional representations (Hill 2010). Each item is rated on a five-point 191 Likert-style scale (Hill 2010). Higher subscale scores reflect greater 
192 endorsement of the given construct (Zoeckler et al. 2014). High scores on

193 consequences, timeline acute/chronic, cyclical and emotional

194 representation subscales represent negative illness beliefs that an illness

195 has adverse impacts, is chronic, cyclical in nature and generates a negative

196 emotional response respectively. Whereas high scores on illness

197 coherence and personal and treatment control indicate positive illness

198 beliefs where individuals understood their condition, felt in control over their

199 condition and the treatment received controls/cures the illness.

201 Statistical methods

202 Data analyses were performed using IBM SPSS statistics for Windows, 203 version 24 (Armonk, NY: IBM Corp). Descriptive statistics were employed

204 for participant characteristics. Continuous variables were described using 205 mean and standard deviation while dichotomous variables were described 206 using percentages. To ensure methodological robustness, non-normal data

207 were transformed first to correct for distributional problems and to achieve 208 normality. Subsequently, all analyses when applicable were bootstrapped

209 using 1000 samples and computed based on a bias-corrected and 210 accelerated (BCa) confidence interval.

212 Pearson correlations were used to investigate the associations between 213 facets of illness representations and levels of physical activity. Hierarchical

214 multiple regression analyses were used to model the relationships between

215 facets of illness representations, levels of physical activity, and participant 216 characteristics. As the study sample size is underpowered, Adjusted R 
217 square values are reported (Pallant 2007). A post-hoc regression analysis

218 was conducted with only the predictors that made a statistically significant

219 contribution to the main regression analysis to address the small sample

220 size issue. Mediation and moderation analyses were performed using

221 Hayes' PROCESS macro for SPSS (Hayes 2012) to investigate the role of

222 depression in the hypothesised relationship between dimensions of illness

223 representations and level of physical activities.

225 For missing data, cases were excluded from the calculation of overall BDI

226 score if there were more than one missing datum. On the IPQ-R, cases

227 were excluded if more than two items are missing per subscale with the

228 exception of subscales with less than six items where a maximum of one

229 missing item is allowed. Expectation maximisation was used to manage the

230 missing data for IPAQ-SF for correlation and regression analyses. Little's

231 Missing Completely at Random (MCAR) test was run to ensure that missing

232 data for IPAQ-SF were completely random (Little 1988). 'Treatment Control'

233 subscale was excluded from regression analyses as the sample consisted

234 of non-dialysing participants with conservative treatment. The subscale was

235 considered lacking salience in predicting levels of physical activity, and

236 simple correlation examined between treatment control and levels of

237 physical activity yielded no significant association. All statistical analyses

238 adopted a pairwise exclusion method. 


\section{Results}

242 Patient characteristics

243164 patients were approached, of these, 64 declined to take part in the

244 study. 100 patients consented to participate, but 30 did not return the survey

245 booklet and were withdrawn from the study. The final sample comprised 70

246 patients with CKD-ND (43\% participation rate). The majority of these were

247 male (60\%), identified as 'White British' (80\%), with a mean age of $60 \pm 16$

248 years. Demographics and clinical data are reported in Table 1.

$250 \quad[$ Table 1]

251

252 Levels of physical activity

253 Approximately a third of the participants (35\%) were sedentary, meeting the

254 criteria of low/inactive level of physical activity, and thus considered

255 insufficiently active. Whereas $39 \%$ individuals met the criteria of 'Minimally

256 Active', achieving the recommended minimum level of activity for adults, but

257 insufficient when considering total level of physical activity. Only $26 \%$ of the

258 sample met the HEPA active category, which describes individuals as

259 exceeding the minimum public health physical activity guidelines and

260 leading a healthy lifestyle. The sample's median level of physical activity

261 expended per week is 1386 MET-min, which meets the category 'Minimally

262 Active'. 
264 Participants generally reported 'Minimal Depression' with $63.2 \%$ of 265 participants' scores in this category, $17.6 \%$ for 'Mild Depression, $11.8 \%$ for

266 'Moderate Depression' and 7.4\% for 'Severe Depression' (Table 2). The

267 mean BDI-II score for the sample was $12.0 \pm 9.6$ with a range of $0-45$. Half $268(50 \%)$ of the participants had a BDI-II cut-off score of $\geq 11$.

$270 \quad$ [Table 2]

271

272 Association of illness representations with levels of physical activity

273 There was a small positive correlation between personal control and level 274 of physical activity $(r=.288, p=.034)$, suggesting that individuals who 275 perceived themselves as having more personal control were more likely to 276 engage in higher levels of physical activity. Correlations between timeline

277 cyclical and levels of physical activity approached statistical significance ( $r=-$ $278.242, p=.078)$. No other components of illness representations were 279 significantly associated with levels of physical activity. Findings are 280 presented in Table 3.

282 [Table 3]

283

284 Primary regression analysis

285 The change in Adjusted $R$ Square scores $\left(\Delta R^{2}\right.$ Adjusted $\left.=.142, p=.027\right)$ 286 indicated that illness representation components accounted for $14.2 \%$ of the 287 variance in IPAQ-SF scores after effects of age and eGFR were removed 
288 (Table 4). Of illness representation components, only timeline cyclical 289 (Beta=-.423, $p=.008$ ) made a statistically significant contribution to the 290 variance reported. Overall, Model 2 is significantly better at predicting the

291 outcome with improvement greater than the inaccuracy within the model $292(F(8,47)=3.23, p=.005)$. The variables in Model 2 , including age and eGFR, 293 contributed to $24.5 \%$ of the variance in IPAQ-SF scores $\left(R^{2}\right.$ djusted $=.245$, $294 p=.027)$. Other than time cyclical, age is the only other predictor that made

295 a significant unique contribution in Model 2 (Beta=-.353, $p=0.41)$. Timeline 296 cyclical made the largest unique contribution between the two predictors.

298 [Table 4]

300 Post-hoc regression analysis

301 A post-hoc hierarchical multiple regression analysis (Table 5) was

302 conducted with the significant predictors from the main analysis, age and

303 timeline cyclical, as variables. Timeline cyclical accounted for $8.1 \%$ of the

304 variance in IPAQ-SF scores after controlling for age $\left(\Delta R^{2}\right.$ Adjusted $=.081$, $305 p=.009$ ) while Model 2 as a whole explains $21.1 \%$ of the variance $306\left(R^{2}\right.$ Adjusted=.211, $\left.p=.009\right)$. Both timeline cyclical (Beta $\left.=-.312, p=.005\right)$ and 307 age (Beta=-.451, $p=.011$ ) made a statistically significant contribution to the 308 variance reported. Overall, Model 2 significantly improved the predictability 309 of IPAQ-SF scores compared to not fitting the model $(F(2,61)=9.44$, $310 p<.001)$

312 [Table 5] 
314 Moderation and mediation analyses

315 Moderation analysis was conducted with levels of physical activity (IPAQ-

316 SF) as the dependent variable, timeline cyclical as the independent variable

317 and severity of depression (BDI-II) as the moderator variable (Table 6).

318 Findings suggest that the relationship between timeline cyclical and levels

319 of physical activity is not moderated by severity of depression as the

320 interaction effect is not significant $(b=.023,95 \% \mathrm{Cl}[-.015, .061], t=1.201$, $321 p=.23)$.

322

323 [Table 6]

324

325 Similarly, mediation analysis (Figure 1) was conducted with levels of 326 physical activity (IPAQ-SF) as the dependent variable, timeline cyclical as

327 the independent variable and severity of depression (BDI-II) as the mediator

328 variable. Results indicated that severity of depression was not a mediator

329 as there is no significant indirect effect of timeline cyclical on levels of

330 physical activity through severity of depression $(b=-.021, \mathrm{BCa} \mathrm{Cl}[-.082$,

$331.008], p=.33)$.

332

333 [Figure 1] 


\section{Discussion}

337 The present study is the first to examine the relationship between illness

338 representations and levels of physical activity in patients with CKD-ND.

339 Findings of this study suggest that illness representation elements are

340 associated with, and predictive of, levels of physical activity in accordance

341 with the CSM model assumptions, in which perceptions of a condition such

342 as CKD influence coping and the utilisation of health behaviours (Leventhal

343 et al. 1984). Regarding the secondary aim, depression was not found to

344 mediate or moderate the predictive relationship between timeline cyclical

345 and levels of physical activity.

347 Almost three-quarter of the sample (74\%) undertook insufficient levels of

348 physical activity. This is expected as CKD has been found to be associated

349 with impaired physical activity (Beddhu et al. 2009). Half of the sample had

350 a BDI-II cut-off score of $\geq 11$, which is indicative of a depressive

351 presentation. This rate is more than twice reported in a systematic review

352 on the prevalence of depression in CKD (Palmer et al. 2013). The reason

353 for this discrepancy is unclear. Our study sample comprised only patients

354 with CKD-ND, thus excluding those receiving renal replacement therapy or

355 had kidney transplants.

357 Regarding associative relationship, only personal control had a statistically

358 significant positive correlation with levels of physical activity, suggesting that

359 patients with CKD-ND who perceived themselves as having more control 
360 over their illness were more likely to engage and undertake higher levels of

361 physical activity. This is consistent with Hagger and Orbell (2003) meta-

362 analysis examining the relationship between illness representations and

363 health behaviours and illness outcomes. They found that CSM cure/control

364 dimension, equivalent to personal control, was positively correlated with

365 specific problem-focused coping strategies such as exercise (Hagger \&

366 Orbell 2003). Perception of personal control over illness was related to

367 active coping strategies, which was reflected in our results. In the context of

368 CKD, where the main goal of physical activity is to improve disease

369 management as opposed to cure, it could define an important coping

370 strategy. Similarly, the French et al. (2006) systematic review with meta-

371 analysis reported patients with cardiovascular disease (CVD) disclosing

372 greater CSM cure/control appraisals were more likely to attend cardiac

373 rehabilitation, indicating active coping through the engagement of health

374 behaviour. The positive association between personal control and levels of

375 physical activity has also been established in CVD research studies (Reges

376 et al. 2013; Mosleh \& Almalik 2016).

377

378 Timeline cyclical dimension predicted levels of physical activity and

379 remained statistically significant for the post-hoc regression analysis.

380 Patients with CKD-ND who considered their illness and symptoms as

381 unpredictable and cyclical undertook lower levels of physical activity. This

382 finding parallels Sniehotta et al. (2010) who similarly concluded that timeline

383 cyclical predicted levels of physical activity in patients with CVD. It is

384 possible that patients with CKD-ND who perceived their condition as cyclical 
385 may adopt an avoidant coping style by not employing health behaviours for

386 the fear of aggravating their symptoms (Sniehotta et al. 2010). Such

387 explanation is congruent with Hagger and Orbell (2003) who found that the

388 timeline dimension, which consists of both acute/chronic and cyclical

389 components, were positively associated with avoidance and denial.

391 The predictive relationship between timeline cyclical and levels of physical

392 activity were neither moderated nor mediated by the severity of depression.

393 This is expected as severity of depression was not significantly associated

394 with levels of physical activity. One possible explanation for the lack of

395 significance was that missing data in the IPAQ-SF, substituted by

396 suggested values through expectation maximisation technique, could have

397 influenced the statistical significance. This appears confirmed by a post-hoc

398 simple correlation analysis using the original IPAQ-SF data with no data

399 imputation where results indicated a significant negative relationship

400 between severity of depression and levels of physical activity.

401

$402 \quad$ Limitations

403 There are several limitations in the current study. Whilst our findings have

404 shown a relationship between illness representations and physical activity,

405 only two of the seven domains of the CSM were statistically significant,

406 indicating a limitation of the CSM as an explanatory model for physical

407 activity behaviour. Results emerged from a within group cross-sectional

408 survey design, which precluded causal examination and comparisons

409 across groups. Additionally, the self-report measures (IPAQ-SF and BDI-II) 
410 are prone to recall bias, which threatens the validity of the data (Raphael

411 1987). We acknowledge the small sample size and made stringent attempts

412 to address power: a post-hoc regression analysis with two predictor

413 variables was conducted, which met the 15 cases per predictor variable

414 requirement for social sciences research (Stevens 1996). Future studies

415 could address the power issue by recruiting a larger sample and refining

416 data collection method, such as using online survey systems. With

417 participant characteristics of the sample indicating more males than the

418 prevalence model (Roth et al. 2010), and the sample reporting more

419 depression compared to other studies (Palmer et al. 2013), results are not

420 entirely generalisable to the CKD population, and are restricted to patients

421 with CKD-ND. Our study population also had a higher percentage of White

422 British participants (80\%) than the local CKD population (70\%). These

423 differences possibly could be due to the sampling method adopted, which

424 results in selection bias (Acharya et al. 2013). Moreover, individuals who

425 declined to take part in the study may differ from those who volunteered for

426 the study, resulting in non-response bias (Sedgwick 2014).

428 Implications for clinical practice

429 Our study results suggest a predictive relationship between timeline cyclical

430 and levels of physical activity, which are neither moderated nor mediated

431 by the severity of depression. This demonstrates that timeline cyclical is an

432 important predictor and on its own has a direct effect on levels of physical

433 activity. This is a key finding, with important clinical implications given the

434 substantial evidence that patients with CKD undertake insufficient physical 
435 activity (Zamojska et al. 2006; Beddhu et al. 2009; Avesani et al. 2012;

436 Hayhurst \& Ahmed 2015), with potential adverse consequences (Beddhu et

437 al. 2009; Zelle et al. 2017). Furthermore, research has found that exercise

438 is beneficial for patients with CKD (Heiwe 2011) and associated with better

439 outcomes (Tentori et al. 2010), including non-dialysing patients (Gould et 440 al. 2014).

442 Given that components of illness representations appeared to underpin and

443 direct the motivation to engage in physical activity, better understanding and

444 targeting of patient appraisals in this population appears warranted. Clinical

445 resources could be invested for nurses to conduct routine psychological 446 assessment and screening for patients with CKD-ND, to assess their illness

447 representations. Development of psychological interventions specifically to

448 address unhelpful representations could also be considered and delivered

449 by trained nursing staff (Hale et al. 2007, Hudson et al. 2016). For instance,

450 psychoeducation on CKD could be provided to increase patients'

451 understanding and knowledge of the condition, which could potentially

452 empower them and increase personal control. With enhanced knowledge,

453 individuals could identify early warning signs of their symptoms, and work

454 with health providers to better manage their condition to enhance stability

455 and prevent deterioration. Enhanced awareness and active illness

456 management could mitigate perceptions of illness unpredictability and

457 improve perceived controllability. Research has established the efficacy of

458 illness representations-based interventions in increasing physical activity in

459 patients after myocardial infarction (Broadbent et al. 2009), and improving 
460 clinical and psychological outcomes in diabetic patients (Keogh et al. 2011).

461 Similarly, such focused interventions should be timely provided for patients

462 with CKD-ND to enhance and sustain uptake of physical activity and 463 potentially mitigate the effects of depression.

464 


\section{Conclusion}

466 The current study has established the relationship of illness representations

467 with levels of physical activity. Future research concerning the development

468 and validation of psychological interventions specific to the modification of

469 illness representations in patients with CKD-ND is encouraged. In addition,

470 robust design adopting randomised controlled method could examine

471 efficacy of such treatments and establish causal links between illness

472 representations and levels of physical activity.

473 


\section{$474 \quad$ References}

475

476 Acharya A. S., Prakash A., Saxena, P. et al. (2013). Sampling: Why and

477 how of it. Indian Journal of Medical Specialities, 4(2), 330-333.

478

479 Avesani C.M., Trolonge S., Deleaval P. et al. (2012). Physical activity and

480 energy expenditure in haemodialysis patients: an international

481 survey. Nephrology, Dialysis, Transplantation 27(6), 2430-2434.

482

483 Beck A.T., Steer R.A. \& Brown G.K. (1996). Beck depression inventory-

484 II. San Antonio 78(2), 490-498.

485

486 Beck A.T., Steer R.A. \& Carbin M.G. (1988). Psychometric properties of

487 the Beck Depression Inventory: Twenty-five years of evaluation. Clinical

488 Psychology Review 8(1), 77-100.

489

490 Beddhu S., Baird B.C., Zitterkoph J. et al. (2009). Physical activity and

491 mortality in chronic kidney disease (NHANES III). Clinical Journal of the

492 American Society of Nephrology 4(12), 1901-1906.

493

494 Broadbent E., Ellis C.J., Thomas J. et al. (2009). Further development of

495 an illness perception intervention for myocardial infarction patients: a

496 randomized controlled trial. Journal of Psychosomatic Research 67(1), 17 -

49723.

498 
499 Craig C.L., Marshall A.L., Sjostrom M. et al. (2003). International physical

500 activity questionnaire: 12-country reliability and validity. Medicine and

501 Science in Sports and Exercise 35(8), 1381-1395.

502

503 Cruz L.N., de Almeida Fleck M.P. \& Polanczyk C.A. (2010). Depression as

504 a determinant of quality of life in patients with chronic disease: data from

505 Brazil. Social psychiatry and psychiatric epidemiology 45(10), 953-961.

506

507 Cukor D., Coplan J., Brown C. et al. (2007). Depression and anxiety in

508 urban hemodialysis patients. Clinical Journal of the American Society of

$509 \quad$ Nephrology 2(3), 484.

510

511 East Midlands Public Health Observatory. (2010). Kidney disease: key

512 facts and figures. Retrieved from:

513 http://www.boltonshealthmatters.org/sites/default/files/Kidney-Disease-

514 Key-Facts.pdf

516 Farrokhi F., Abedi N., Beyene J. et al. (2014). Association between

517 depression and mortality in patients receiving long-term dialysis: a

518 systematic review and meta-analysis. American journal of kidney diseases

519 63(4), 623-635.

520

521 French D.P., Cooper A. \& Weinman J. (2006). Illness perceptions predict

522 attendance at cardiac rehabilitation following acute myocardial infarction: a 
523 systematic review with meta-analysis. Journal of Psychosomatic

524 Research 61(6), 757-767.

525

526 Gould D.W., Graham-Brown M.P., Watson E.L. et al. (2014). Physiological

527 benefits of exercise in pre-dialysis chronic kidney

528 disease. Nephrology 19(9), 519-527.

529

530 Hagger M.S. \& Orbell S. (2003). A meta-analytic review of the common-

531 sense model of illness representations. Psychology and Health 18(2), 141532184.

533

534 Hale E.D., Treharne G.J. \& Kitas G.D. (2007). The common-sense model

535 of self-regulation of health and illness: how can we use it to understand

536 and respond to our patients' needs? Rheumatology 46(6), 904-906.

537

538 Hayes A.F. (2012). An analytical primer and computational tool for

539 observed variable moderation, mediation, and conditional process

540 modeling. Retrieved from http://www.afhayes.com/public/process2012.pdf 541

542 Hayhurst W.S. \& Ahmed A. (2015). Assessment of physical activity in

543 patients with chronic kidney disease and renal replacement

544 therapy. Springerplus 4(1), 536. 
546 Hedayati S.S., Yalamanchili V. \& Finkelstein F.O. (2012). A practical

547 approach to the treatment of depression in patients with chronic kidney

548 disease and end-stage renal disease. Kidney International 81(3), 247-255.

549

550 Hedayati S.S., Minhajuddin A.T., Toto R.D. et al. (2009). Prevalence of

551 major depressive episode in CKD. American Journal of Kidney

552 Diseases 54(3), 424-432.

553

554 Heiwe S. \& Jacobson S.H. (2011). Exercise training for adults with chronic

555 kidney disease. Cochrane Databse Syst Rev 10(10)

556

557 Hill S. (2010). The illness perceptions questionnaire-revised (IPQ-

558 R). Journal of Physiotherapy 56(4), 280.

559

560 Hudson J.L., Moss-Morris R., Game, D. et al. (2016). Improving distress in

561 dialysis (iDiD): a feasibility two-arm parallel randomised controlled trial of

562 an online cognitive behavioural therapy intervention with and without

563 therapist-led telephone support for psychological distress in patients

564 undergoing haemodialysis. BMJ open 6(4), p.e011286.

565

566 IPAQ. (2005). Guidelines for data processing and analysis of the

567 International Physical Activity Questionnaire (IPAQ)-short and long

568 forms. Retrieved from https://sites.google.com/site/theipaq/scoring-

569 protocol/scoring protocol. pdf?attredirects $=0 \& \mathrm{~d}=1$ 
571 Jansen D. L., Grootendorst D. C., Rijken M. et al. (2010). Pre-dialysis

572 patients' perceived autonomy, self-esteem and labor participation:

573 associations with illness perceptions and treatment perceptions. A cross-

574 sectional study. BMC nephrology 11(1), 35.

575

576 Jansen D. L., Heijmans M. J., Rijken M. et al. (2013). Illness perceptions

577 and treatment perceptions of patients with chronic kidney disease:

578 different phases, different perceptions?. British journal of health

579 psychology 18(2), 244-262.

580

581 Jekauc D. \& Brand R. (2017). How do Emotions and Feelings Regulate

582 Physical Activity?. Frontiers in Psychology 8, 1145.

584 Keogh K.M., Smith S.M., White P. et al. (2011). Psychological family

585 intervention for poorly controlled type 2 diabetes. The American Journal of 586 Managed Care 17(2), 105-113.

588 Kosmadakis G., John S., Clapp E.L., et al. (2012). Benefits of regular 589 walking exercise for patients with severe pre-dialysis chronic kidney 590 disease. Nephrol Dial Transplant 27(3),997-1004.

591

592 Leventhal H., Nerenz D.R. \& Steele D.J. (1984). IIIness representations

593 and coping with health threats. In Handbook of Psychology and Health

594 (eds Baum A., Taylor S.E., Singer J.E.), pp. 219-252. Hillsdale, NJ:

595 Lawrence Erlbaum Associates. 
597 Leventhal H. \& Cleary P.D. (1980). The smoking problem: a review of the

598 research and theory in behavioral risk modification. Psychological

599 Bulletin 88(2), 370.

600

601 Little R.J. (1988). A test of missing completely at random for multivariate

602 data with missing values. Journal of the American Statistical

603 Association 83(404), 1198-1202.

604

605 Mosleh S.M. \& Almalik M.M. (2016). Illness perception and adherence to

606 healthy behaviour in Jordanian coronary heart disease patients. European

607 Journal of Cardiovascular Nursing 15(4), 223-230.

608

609 Moss-Morris R., Weinman J., Petrie K. et al. (2002). The revised illness

610 perception questionnaire (IPQ-R). Psychology and Health 17(1), 1-16.

611

612 Muscat P., Chilcot J., Weinman J. et al. (2018). Exploring the relationship

613 between illness perceptions and depression in patients with chronic kidney

614 disease: A systematic literature review. Journal of Renal Care $\mathbf{0}(0), 1-12$.

616 National Institute for Health and Care Excellence (2015a). Chronic kidney

617 disease in adults: assessment and management. Introduction. Retrieved

618 from: https://www.nice.org.uk/guidance/cg182/chapter/Introduction 
620 National Institute for Health and Care Excellence (2015b). Chronic kidney

621 disease in adults: assessment and management. Research

622 recommendations. Retrieved from:

623 https://www.nice.org.uk/guidance/cg182/chapter/3-Research-

624 recommendations

625

626 Nigg C.R., Allegrante J.P. \& Ory M. (2002). Theory-comparison and

627 multiple-behavior research: common themes advancing health behavior

628 research. Health Education Research 17(5), 670-679.

629

630 Pallant J. (2013). SPSS Survival Manual. UK: McGraw-Hill Education.

631

632 Palmer S., Vecchio M., Jonathan C.C. et al. (2013). Prevalence of

633 depression in chronic kidney disease: systematic review and meta-

634 analysis of observational studies. Kidney International 84(1), 179-191.

635

636 Raphael K. (1987). Recall bias: a proposal for assessment and

637 control. International Journal of Epidemiology 16(2), 167.

638

639 Reges O., Vilchinsky N., Leibowitz M. et al. (2013). Illness cognition as a

640 predictor of exercise habits and participation in cardiac prevention and

641 rehabilitation programs after acute coronary syndrome. BMC Public

$642 \quad$ Health 13(1), 956.

643 
644 Roth M., Roderick P. \& Mindell J. (2010). Kidney disease and renal

645 function. Health Survey for England 1.

646

647 Sedgwick P. (2014). Cross sectional studies: advantages and

648 disadvantages. BMJ: British Medical Journal 348.

649

650 Smith A.C. and Burton J.O. (2012). Exercise in Kidney Disease and

651 Diabetes : Time For Action. Journal of Renal Care 38(Suppl 1), 52-58.

652

653 Sniehotta F.F., Gorski C. \& Araújo-Soares V. (2010). Adoption of

654 community-based cardiac rehabilitation programs and physical activity

655 following phase III cardiac rehabilitation in Scotland: A prospective and

656 predictive study. Psychology \& Health 25(7), 839-854.

657

658 Stevens, J.P. (2012). Analysis of covariance. In Applied Multivariate

659 Statistics for the Social Sciences, Fifth Edition (pp. 299-326). Routledge.

660

661 Teles F., Azevedo V.F.D.D., Miranda C.T.D. et al. (2014). Depression in

662 hemodialysis patients: the role of dialysis shift. Clinics 69(3), 198-202.

663

664 Tentori F., Elder S.J., Thumma J. et al. (2010). Physical exercise among

665 participants in the Dialysis Outcomes and Practice Patterns Study

666 (DOPPS): correlates and associated outcomes. Nephrology, Dialysis,

667 Transplantation 25(9), 3050-3062.

668 
669 Tonelli M., Wiebe N., Guthrie B. et al. (2015). Comorbidity as a driver of

670 adverse outcomes in people with chronic kidney disease. Kidney

671 international 88(4), 859-866.

672

673 Wilkinson T.J., Watson E.L., Gould D.W. et al. (2018). Twelve weeks of

674 supervised exercise improves self-reported symptom burden and fatigue in

675 chronic kidney disease: a secondary analysis of the 'ExTra CKD' trial.

676 Clinical Kidney Journal, in press doi: 10.1093/ckj/sfy071

677

678 Whisman M.A. \& Richardson E.D. (2015). Normative data on the Beck

679 Depression Inventory-second edition (BDI-II) in college students. Journal

680 of Clinical Psychology 71(9), 898-907.

681

682 Zamojska S., Szklarek M., Niewodniczy M. et al. (2006). Correlates of

683 habitual physical activity in chronic haemodialysis patients. Nephrology,

684 Dialysis, Transplantation 21(5), 1323-1327.

685

686 Zelle D.M., Klaassen G., van Adrichem E. et al. (2017). Physical inactivity:

687 a risk factor and target for intervention in renal care. Nature Reviews

688 Nephrology 13(3), 152.

689

690 Zoeckler N., Kenn K., Kuehl K. et al. (2014). Illness perceptions predict

691 exercise capacity and psychological well-being after pulmonary

692 rehabilitation in COPD patients. Journal of Psychosomatic Research

$693 \quad 76(2), 146-151$. 


\section{Tables}

695

696 Table 1: Sample characteristics

697

Study sample $(n=70)$

\begin{tabular}{|c|c|}
\hline Age & \\
\hline Mean age (SD) & $60.1(15.9)$ \\
\hline Median age (in years) & 60 \\
\hline Age range (\%) & \\
\hline $18-39$ years & $8(11.4 \%)$ \\
\hline $40-59$ years & $26(37.1 \%)$ \\
\hline 60 years and above & $36(51.4 \%)$ \\
\hline Gender (\%) & \\
\hline Male & $42(60 \%)$ \\
\hline Female & $28(40 \%)$ \\
\hline Ethnicity $(n=67)$ & \\
\hline White British & 56 \\
\hline Indian & 7 \\
\hline White any other background & 1 \\
\hline White and Black Carribean & 1 \\
\hline White Asian & 1 \\
\hline Pakistani & 1 \\
\hline Level of Education (n=68) (\%) & \\
\hline Lower Secondary Qualification & $17(25 \%)$ \\
\hline Upper Secondary Qualification & $6(8.8 \%)$ \\
\hline University or College below a degree & $16(23.5 \%)$ \\
\hline University or College degree & $15(22.1 \%)$ \\
\hline None of these & $14(20.6 \%)$ \\
\hline Smoking Status (\%) & \\
\hline Never smoked & $37(52.9 \%)$ \\
\hline Current smoker & $5(7.1 \%)$ \\
\hline Ex-smoker & $28(40 \%)$ \\
\hline Comorbidity Reported (n=66) (\%) & \\
\hline Yes & $50(75.8 \%)$ \\
\hline No & $16(24.2 \%)$ \\
\hline Stage of CKD (\%) & \\
\hline Stage 1 & $2(2.9 \%)$ \\
\hline
\end{tabular}


Stage 2

Stage 3

Stage 4

Stage 5

Onset of CKD (n=69)

Onset of CKD range (in months)

Mean onset of CKD in months (SD)

eGFR $(\mathrm{n}=68)\left(\mathrm{ml} / \mathrm{min} / 1.73 \mathrm{~m}^{2}\right)$

eGFR range

Mean eGFR (SD)
$16(22.9 \%)$

$14(20 \%)$

$32(45.7 \%)$

$6(8.6)$

$0.5-360$ $110.6(100.6)$

$8-90$

$34.5(22.3)$

698

699 
700 Table 2: BDI-II results summary

Study sample $(n=68)$

Depression severity category (\%)

Minimal Depression

$43(63.2 \%)$

Mild Depression

$12(17.6 \%)$

Moderate Depression

$8(11.8 \%)$

Severe Depression

$5(7.4 \%)$

$B D I$ score

Mean BDI score (SD)

$12.0(9.6)$

BDI cut-off score criteria (\%)

BDI score $\geq 11$

$34(50 \%)$

701

702 
Table 3: Correlations for participant characteristics, levels of physical activity, illness representations and severity of depression

\begin{tabular}{|c|c|c|c|c|c|c|c|c|c|c|c|}
\hline & \multicolumn{2}{|c|}{$\begin{array}{c}\text { Participant } \\
\text { Characteristics }\end{array}$} & \multicolumn{7}{|c|}{ IPQ-R } & \multirow{2}{*}{$\begin{array}{c}\text { IPAQ-SF } \\
10\end{array}$} & \multirow{2}{*}{$\begin{array}{c}\text { BDI-II } \\
11\end{array}$} \\
\hline & 1 & 2 & 3 & 4 & 5 & 6 & 7 & 8 & 9 & & \\
\hline 1. Age & - & $-.277 *$ & -.042 & $-.310^{*}$ & -.096 & -.132 & -.134 & .013 & $-.368^{* *}$ & $-.291 *$ & -.168 \\
\hline 2. eGFR & & - & .095 & -.073 & $-.425 * *$ & .125 & -.134 & .087 & -.035 & .227 & -.010 \\
\hline $\begin{array}{l}\text { 3. Timeline } \\
\text { (Acute/Chronic) }\end{array}$ & & & - & .041 & -.136 & .113 & $.489 * *$ & -.268 & -.067 & .071 & -.154 \\
\hline 4. Timeline Cyclical & & & & - & $.403 * *$ & -.073 & .178 & -.245 & $.470 * *$ & -.242 & $.582 * *$ \\
\hline 5. Consequences & & & & & - & -.197 & -.016 & -.165 & $.430 * *$ & -.109 & $.463^{* *}$ \\
\hline 6. Personal Control & & & & & & - & $.475 * *$ & $.435 * *$ & $-.366^{* *}$ & $.288^{*}$ & $-.354 * *$ \\
\hline 7. Treatment Control & & & & & & & - & .079 & -.153 & .125 & -.071 \\
\hline 8. Illness Coherence & & & & & & & & - & $-.544 * *$ & -.042 & $-.277 *$ \\
\hline $\begin{array}{l}\text { 9. Emotional } \\
\text { Representations }\end{array}$ & & & & & & & & & - & -.003 & $.654^{* *}$ \\
\hline 10. IPAQ-SF & & & & & & & & & & - & -.245 \\
\hline $\begin{array}{l}\text { 11. Overall BDI-II } \\
\text { Score }\end{array}$ & & & & & & & & & & & - \\
\hline
\end{tabular}


Table 4: Multiple regression analysis for levels of physical activity (IPAQ-SF), with $95 \%$ BCa confidence intervals reported in parentheses. Confidence intervals and standard errors based on 1000 bootstrap samples

\begin{tabular}{|c|c|c|c|c|c|c|c|c|}
\hline \multirow[b]{2}{*}{ Variable } & \multicolumn{4}{|c|}{ Model 1} & \multicolumn{4}{|c|}{ Model 2} \\
\hline & $b$ & $S E B$ & $\boldsymbol{\beta}$ & $p$ (2-tailed) & $B$ & $S E B$ & $\boldsymbol{\beta}$ & $p$ (2-tailed) \\
\hline Age & $\begin{array}{c}-.016 \\
(-.035,-.001)\end{array}$ & .009 & -.277 & .081 & $\begin{array}{c}-.021 \\
(-.039,-.004)\end{array}$ & .009 & -.353 & .041 \\
\hline eGFR & $\begin{array}{c}.541 \\
(-.194,1.323)\end{array}$ & .360 & .171 & .138 & $\begin{array}{c}.450 \\
(-.399,1.264)\end{array}$ & .448 & .143 & .358 \\
\hline $\begin{array}{c}\text { Timeline } \\
\text { Acute/Chronic }\end{array}$ & & & & & $\begin{array}{c}-.052 \\
(-.246, .137)\end{array}$ & .114 & -.057 & .656 \\
\hline Timeline Cyclical & & & & & $\begin{array}{c}-.106 \\
(-.181,-.029)\end{array}$ & .036 & -.423 & .008 \\
\hline Consequences & & & & & $\begin{array}{c}.016 \\
(-.044, .078)\end{array}$ & .031 & .101 & .612 \\
\hline Personal Control & & & & & $\begin{array}{c}.067 \\
(.005, .137)\end{array}$ & .036 & .343 & .093 \\
\hline Illness Coherence & & & & & $\begin{array}{c}-.057 \\
(-.118, .009)\end{array}$ & .033 & -.307 & .106 \\
\hline $\begin{array}{c}\text { Emotional } \\
\text { Representations }\end{array}$ & & & & & $\begin{array}{c}-.002 \\
(-.068, .060)\end{array}$ & .035 & -.011 & .968 \\
\hline
\end{tabular}

Note: $\mathrm{R}^{2}=.136$ and $\mathrm{R}^{2}$ Adjusted $=.103$ for Model $1 ; \Delta \mathrm{R}^{2}=.219$ and $\Delta \mathrm{R}^{2}$ ddjusted $=.142$ for Model $2(p \mathrm{~s}<.05)$. 
Table 5: Post-hoc regression analysis for levels of physical activity (IPAQ$\mathrm{SF})$, with $95 \% \mathrm{BCa}$ confidence intervals reported in parentheses. Confidence intervals and standard errors based on 1000 bootstrap samples

\begin{tabular}{|c|c|c|c|c|}
\hline & $b$ & $S E B$ & $\beta$ & $p$ (2-tailed) \\
\hline \multicolumn{5}{|l|}{ Model 1} \\
\hline Age & $\begin{array}{c}-.023 \\
(-.039,-.009)\end{array}$ & .008 & -.380 & .017 \\
\hline \multicolumn{5}{|l|}{ Model 2} \\
\hline Age & $\begin{array}{c}-.028 \\
(-.046,-.012)\end{array}$ & .008 & -.451 & .011 \\
\hline Timeline Cyclical & $\begin{array}{c}-.085 \\
(-.139,-.031)\end{array}$ & .027 & -.312 & .005 \\
\hline
\end{tabular}

Note: $\mathrm{R}^{2}=.144$ and $\mathrm{R}^{2}$ Adjusted $=.130$ for Model $1 ; \Delta \mathrm{R}^{2}=.092$ and $\Delta \mathrm{R}^{2}$ Adjusted $=.081$ for Model $2(p \mathrm{~s}<.01)$. 
Table 6: Moderation analysis for levels of physical activity (IPAQ-SF)

\begin{tabular}{lcccc}
\hline & $\boldsymbol{b}$ & $\boldsymbol{S E} \boldsymbol{B}$ & $\boldsymbol{t}$ & $\boldsymbol{p}$ \\
\cline { 2 - 5 } BDI-II & -.095 & .0825 & -1.153 & .254 \\
Timeline Cyclical & $(-.260, .070)$ & & & .378 \\
BDI-II $\boldsymbol{x}$ & $(-.093, .036)$ & .032 & -.888 & .23 \\
Timeline Cyclical & $(-.015, .061)$ & .0191 & 1.201 & \\
\hline
\end{tabular}

Note: $\mathrm{R}^{2}=.078(p=0.56)$. 
Figure

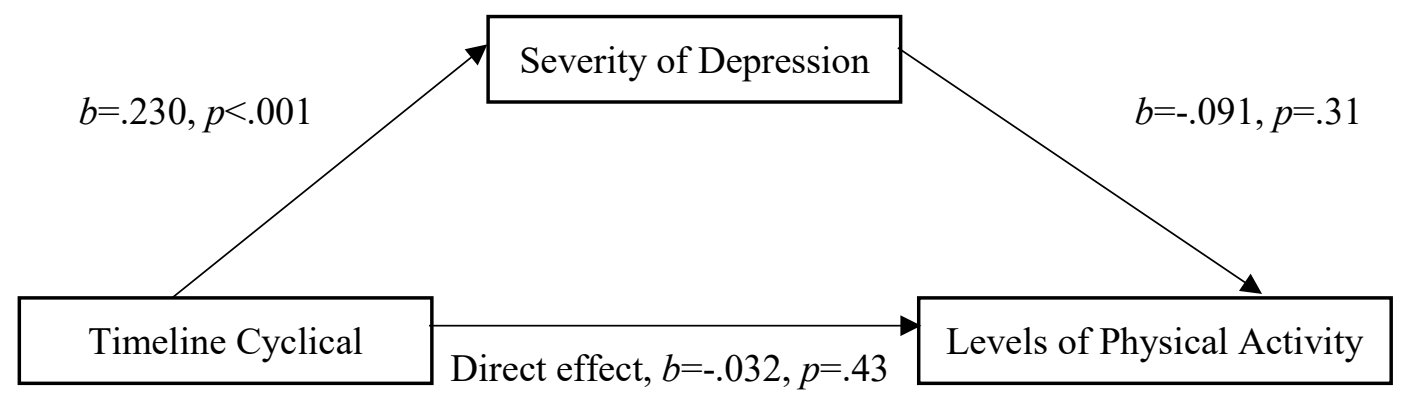

Indirect effect, $b=-.021, p=.33$

Figure 1. Mediation analysis for levels of physical activity (IPAQ-SF). Severity of depression did not act as a mediator as the indirect effect was statistically insignificant. 